\title{
STUDI KEPUSTAKAAN MENGENAI KUALITAS PELAYANAN TERHADAP KEPUASAN PASIEN RAWAT JALAN DI RUMAH SAKIT
}

\section{Literature Study Of Service Quality Towards Patients Satisfaction In Hospitals}

\author{
Aris Dwi Cahyono \\ STIKes Pamenang \\ *Korespondensi Penulis : arisdc81@ gmail.com; +6281359124077
}

\begin{abstract}
Abstrak
Studi kepustakaan ini bertujuan untuk menyusun dan mendeskripsikan kualitas pelayanan terhadap kepuasan pasien rawat jalan di rumah sakit. Metode yang digunakan adalah metode penelitian kepustakaan. Metode pengumpulan data yang digunakan yakni metode dokumentasi. Teknik analisis data yang digunakan adalah analisis isi. Untuk menjaga ketepatan pengkajian dan mencegah kesalahan informasi dalam analisis data maka dilakukan pengecekan antar pustaka dan membaca ulang pustaka serta memperhatikan komentar reviewer. Hasil studi ini adalah menunjukkan bahwa semakin baik kualitas pelayanan rumah sakit yang diberikan kepada pasien maka secara signifikan dapat meningkatkan kepuasan pasien rawat jalan di rumah sakit. Kepuasan pasien tergantung pada kualitas pelayanan. Pelayanan adalah semua upaya yang dilakukan karyawan untuk memenuhi keinginan pelanggannya dengan jasa yang akan diberikan. Kepuasan pelanggan merupakan evaluasi purnabeli dimana alternatif yang dipilih sekurang-kurangnya memberikan hasil sama atau melampaui harapan pelanggan, sedangkan ketidakpuasan timbul apabila hasil yang diperoleh tidak memenuhi harapan pelanggan.
\end{abstract}

Kata Kunci: Kualitas Pelayanan, Kepuasan Pasien, Rumah Sakit

\begin{abstract}
This literature study aims to compile and describe the quality of service to the satisfaction of outpatients in hospitals. The method used was library research. Data collection method used was the documentation method. The data analysis technique used was content analysis. To maintain the accuracy of the assessment and prevent misinformation in data analysis, it was checked between libraries and reread the literature and took into account reviewers' comments. The results of this study indicate that the better the quality of hospital services provided to patients, can significantly increase the satisfaction of outpatients in hospitals. Patient satisfaction depends on the quality of service. Services are all efforts made by employees to meet the desires of their customers with the services to be provided. Customer satisfaction is a full evaluation where the alternative chosen at least gives the same or exceeds customer expectations, while dissatisfaction arises if the results obtained do not meet customer expectations.
\end{abstract}

\section{Keywords: Service Quality, Patient Satisfaction, Hospital}

\section{Pendahuluan}

Pemberian pelayanan secara cepat dan tepat dalam era reformasi dan globalisasi yang sedemikian pesat dan cepat, mutlak dilaksanakan, sebab kalau tidak akan menimbulkan gejolak sosial. Begitu juga halnya mengenai pelayanan di rumah sakit. Pelayanan kesehatan yang belum sesuai dengan harapan pasien, maka diharapkan menjadi suatu masukan bagi organisasi layanan kesehatan agar berupaya

meningkatkan pelayanannya. Jika pelayanan kesehatan yang diperoleh pasien pada suatu fasilitas pelayanan kesehatan sesuai dengan harapannya, masyarakat atau pasien pasti akan selalu datang berobat ke fasilitas pelayanan kesehatan tersebut. Rumah sakit dituntut untuk memberikan pelayanan kesehatan yang memenuhi standar pelayanan yang optimal. Rumah sakit dinyatakan berhasil, tidak hanya pada kelengkapan fasilitas yang diunggulkan, 
melainkan juga sikap dan layanan sumber daya manusia merupakan elemen yang berpengaruh signifikan terhadap pelayanan yang dihasilkan dan dipersepsikan pasien. Pihak Rumah Sakit dituntut untuk selalu menjaga kepercayaan pasien dengan meningkatkan mutu pelayanannya. Rumah sakit sebagai salah satu penyelenggara kesehatan dalam pelaksanaannya dituntut untuk menyediakan pelayanan yang bermutu seperti dalam UU RI No 36 Tahun 2009 Bab 4 Pasal 54 menyebutkan bahwa penyelenggaraan pelayanan kesehatan dilaksanakan secara bertanggung jawab, aman, bermutu, serta merata dan nondiskriminatif. Menurut Azwar, pelayanan kesehatan yang bermutu adalah pelayanan kesehatan yang dapat memuaskan setiap pemakai jasa pelayanan kesehatan sesuai dengan tingkat kepuasan rata-rata penduduk serta yang penyelenggaraannya sesuai dengan standar dan kode etik profesi yang telah ditetapkan. Pelayanan adalah semua upaya yang dilakukan karyawan untuk memenuhi keinginan pelanggannya dengan jasa yang akan diberikan. Menurut Zeithaml, Parasuraman dan Berry (dalam Tjiptono, 1997) terdapat lima dimensi pokok yang berkaitan dengan kualitas jasa yang dikenal dengan teori Service Quality yaitu tangibles, reliability, responsiveness, assurance, dan empathy. Keunggulan layanan tidak akan terwujud jika ada salah satu prinsip pelayanan ada yang dianggap lemah. Pasien mengartikan pelayanan yang bermutu dan efektif adalah jika pelayanannya nyaman, menyenangkan, dan petugasnya ramah yang mana secara keseluruhan memberikan kesan kepuasan terhadap pasien. Sedangkan dari pihak pemberi pelayanan mengartikan pelayanan yang bermutu dan efisien jika pelayanannya sesuai dengan standar pemerintah. Adapun kondisi yang sering dikeluhkan oleh pemakai jasa rumah sakit adalah: sikap dan tindakan dokter atau perawat, sikap petugas administrasi, sarana yang kurang memadai, lambannya pelayanan, persediaan obat, tarif pelayanan, peralatan medis dan lain-lain

\section{Metode}

Penyusunan studi kepustakaan ini menggunakan jenis/pendekatan penelitian yang berupa Studi Kepustakaan (Library Research). Studi kepustakaan merupakan suatu studi yang digunakan dalam mengumpulkan informasi dan data dengan bantuan berbagai macam material yang ada di perpustakaan seperti dokumen, buku, majalah, kisah-kisah sejarah, dsb (Mardalis, 1999 dalam Mirzaqon, 2017). Studi kepustakaan juga dapat mempelajari beberbagai buku referensi serta hasil penelitian sebelumnya yang sejenis yang berguna untuk mendapatkan landasan teori mengenai masalah yang akan diteliti (Sarwono, 2006 dalam Mirzaqon, 2017). Studi kepustakaan juga berarti teknik pengumpulan data dengan melakukan penelaahan terhadap buku, literatur, catatan, serta berbagai laporan yang berkaitan dengan masalah yang ingin dipecahkan (Nazir, 1988 dalam Mirzaqon, 2017). Sedangkan menurut ahli lain studi kepustakaan merupakan kajian teoritis, referensi serta literatur ilmiah lainnya yang berkaitan dengan budaya, nilai dan norma yang berkembang pada situasi sosial yang diteliti (Sugiyono, 2012 dalam Mirzaqon, 2017).

$\begin{array}{rrlr}\text { Metode } & \text { studi } & \text { kepustakaan } & \text { ini } \\ \text { digunakan } & \text { untuk } & \text { menyusun } & \text { dan }\end{array}$
mendeskripsikan kualitas pelayanan terhadap kepuasan pasien rawat jalan di rumah sakit. Adapun langkah-langkah dalam penelitian kepustakaan menurut Kuhlthau (2002) dalam Mirzaqon (2017) adalah sebagai berikut :

1. Pemilihan topik

2. Eksplorasi informasi

3. Menentukan fokus penelitian

4. Pengumpulan sumber data

5. Persiapan penyajian data

6. Penyusunan laporan

Sumber data yang menjadi bahan adalah berupa jurnal dan atau situs internet yang terkait dengan topik yang telah dipilih. Sumber data penelitian ini terdiri dari 7 jurnal tentang kualitas pelayanan terhadap kepuasan pasien rawat jalan di rumah sakit. Teknik pengumpulan informasi melalui dokumentasi, yaitu mencari data mengenai hal-hal atau variabel yang berupa catatan, buku, makalah atau artikel, jurnal dan sebagainya (Arikunto, 2010 dalam Mirzaqon, 2017). Instrumen yang digunakan dalam studi ini adalah daftar check-list klasifikasi bahan penelitian, skema/peta penulisan dan format catatan penelitian. Teknik analisis data yang digunakan adalah metode analisis isi (Content Analysis). Analisis ini digunakan untuk mendapatkan inferensi yang valid dan dapat 
diteliti ulang berdasarkan konteksnya (Kripendoff, 1993 dalam Mirzaqon, 2017). Dalam analisis ini akan dilakukan proses memilih, membandingkan, menggabungkan dan memilah berbagai pengertian hingga ditemukan yang relevan (Serbaguna, 2005 dalam Mirzaqon, 2017). Untuk menjaga proses pengkajian dan mencegah serta mengatasi mis - informasi (kesalahan pengertian manusiawi yang bisa terjadi karena kekurangan penulis pustaka) maka dilakukan pengecekan antar pustaka dan memperhatikan komentar pembimbing (Sutanto, 2005 dalam Mirzaqon, 2017).

\section{Hasil}

1. Penelitian Arifah, 2013 tentang pengaruh kualitas pelayanan terhadap kepuasan pasien rawat jalan di balai besar kesehatan paru masyarakat (BBKPM) Surakarta Hasil penelitian diperoleh persamaan regresi linier berganda adalah: $\mathrm{Y}=$ $-11,917+0,371 \mathrm{X} 1+0,320 \mathrm{X} 2+0,180 \mathrm{X} 3+$ $0,3177 \mathrm{X} 4+0,484 \mathrm{X} 5+0,333 \mathrm{X} 6$. Hasil uji $\mathrm{F}$ diperoleh nilai $F$ hitung sebesar 20,658 dengan nilai signifikansinya adalah $0,000<$ 0,05 sehingga variabel bebas (profesionalism, reliability, attitudes, accesibility, service recovery dan servicecape) secara bersamasama berpengaruh signifikan terhadap variabel terikat (kepuasan pasien). Hasil koefisien determinasi (Adjusted R2) diperoleh sebesar 0,544 artinya variabel (profesionalism, reliability, attitudes, accesibility, service recovery dan servicecape) mampu menjelaskan perubahan terhadap kepuasan pasien sebesar 54,4\%, sedangkan sebesar 45,6,\% dijelaskan oleh variabel di luar model penelitian. Hasil penelitian menunjukkan bahwa nilai beta (standardized coefficient) servicecape 0,326, berarti variabel servicecape merupakan variabel yang paling dominan pengaruhnya terhadap kepuasan pasien.

2. Penelitian Utami, 2013 tentang pengaruh kualitas pelayanan terhadap kepuasan pasien. Hasil penelitian menunjukkan $\mathrm{Uji} F$ dan $\mathrm{Uji}$ t diatas menunjukkan bahwa hipotesis ke-1 penelitian ini dapat terjawab bahwa kualitas pelayanan dengan menggunakan teori Service Quality/Dimensi Kualitas Pelayanan antara lain variabel Tangibles (X1), Reliability (X2), Responsiveness (X3), Assurance (X4) dan Empaty (X5) secara simultan/bersama-sama berpengaruh signifikan terhadap kepuasan pasien. Sedangkan secara parsial, variabel Tangibles (X1), Reliability (X2) dan Empaty (X5) terbukti berpengaruh signifikan terhadap kepuasan (Y). Sedangkan variabel Responsiveness (X3), Assurance (X4) secara parsial tidak terbukti berpengaruh signifikan terhadap kepuasan (Y).

3. Penelitian Rensiner, 2018 tentang analisis faktor kualitas pelayanan terhadap kepuasan pasien rawat jalan RSUD dr. Achmad Darwis. Hasil penelitian menunjukkan uji koefisien determinasi (R2), besaran pengaruh kualitas pelayanan terhadap kepuasan pasien rawat jalan adalah : kualitas pelayanan di loket pendaftaran $57,7 \%$, kualitas pelayanan dokter $55,4 \%$, kualitas pelayanan perawat $63,5 \%$, kualitas pelayanan apotek $27,9 \%$, dan kualitas fasilitas dan lingkungan 40,3\%. Dengan demikian faktor yang paling berpengaruh terhadap kepuasan pasien rawat jalan adalah kualitas pelayanan perawat, yaitu $63,5 \%$. hasil penelitian diperoleh kesimpulan bahwa Terdapat hubungan yang signifikan antara keandalan, ketanggapan, keyakinan, empati dan bukti fisik dengan kepuasan pasien di Poliklinik rawat jalan RSUD Dr. Achmad Darwis Lima Puluh Kota.

4. Penelitian Chairunnisa, 2015 tentang gambaran kepuasan pasien rawat jalan terhadap pelayanan di Rumah Sakit Islam Jakarta Sukapura (RSIJS). Berdasarkan uji IPA hasil pengukuran atribut-atribut pelayanan di RSIJ Sukapura berdasarkan tingkat kepentingan (harapan) dan tingkat pelaksanaannya atau kepuasan (kenyataan) sebagai berikut :

a. Atribut-atribut mutu pelayanan RSIJ Sukapura yang berada pada kuadran A (prioritas utama) adalah : 1) Kebersihan kamar mandi pasien, 2) Kebersihan poli rawat jalan, 3) Ketepatan waktu dokter dalam memulai memberikan pelayanan, 4) Kedisiplinan waktu pelayanan, dan 5) Keramahan dan Kesantunan petugas pendaftaran dan Kasir.

b. Atribut-atribut mutu pelayanan RSIJ Sukapura yang berada pada kuadran B c. (pertahankan prestasi) adalah : 1) Prosedur penerimaan pasien dilayani secara cepat dan tidak terbelit-belit, 2) Kecepatan bagian pendaftaran dan kasir dalam pelayanan, 3) Ketepatan waktu perawat dalam memberikan pelayanan, 4) Cepat tanggap dokter dan 
perawat dalam mengatasi keluhan pasien, 5) Cepat dan tanggap bagian pendaftaran dan kasir dalam membantu pasien, 6) Perawat memperhatikan sungguh-sungguh kepada pasien, dan 7) Pemberian pelayanan terhadap pasien tanpa pilih-pilih.

d. Atribut-atribut mutu pelayanan RSIJ Sukapura yang berada pada kuadran C (prioritas rendah) adalah : 1) Terciptanya suasana kekeluargaan antara perawat dengan pasien, dan 2) Adanya TV diruang tunggu.

e. Atribut yang berada pada kuadran D (berlebihan) adalah: 1) Kebersihan dan kenyamanan ruang tunggu, 2) Dokter memberikan waktu pelayanan yang cukup pada pasien, 3) Terciptanya suasana kekeluargaan antara dokter dan Pasien, 4) Dokter memberikan kesempatan bertanya kepada pasien, 5) Adanya kotak saran untuk kritik dan keluhan, dan 6) Tenaga medis dan karyawan rumah sakit berpenampilan rapi dan bersih.

5. Penelitian Supartiningsih, 2017 tentang Kualitas Pelayanan Kepuasan Pasien Rumah Sakit (Kasus Pada Pasien Rawat Jalan). Hasil penelitian menunjukkan Variabel bukti fisik (tangible) mempunyai pengaruh negatif dan tidak signifikan terhadap kepuasan pasien rumah sakit Sarila Husada Sragen pada pasien Rawat Jalan. Hipotesis ditolak. Variabel keandalan (reliability) mempunyai pengaruh positif dan signifikan terhadap kepuasan pasien rumah sakit Sarila Husada Sragen pada pasien Rawat Jalan. Hipotesis diterima. Variabel daya tanggap (responsiveness) mempunyai pengaruh positif dan tidak signifikan terhadap kepuasan pasien rumah sakit Sarila Husada Sragen pada pasien Rawat Jalan. Hipotesis diterima. Variabel jaminan (assurance) mempunyai pengaruh positif dan signifikan terhadap kepuasan pasien rumah sakit Sarila Husada Sragen pada pasien Rawat Jalan. Hipotesis diterima. Variabel empati (emphaty) mempunyai pengaruh negatif dan tidak signifikan terhadap kepuasan pasien rumah sakit Sarila Husada Sragen pada pasien Rawat Jalan. Hipotesis ditolak. Dari hasil analisis menunjukan bahwa variabel bebas yang paling rendah memberikan pengaruh pada kepuasan pelanggan adalah tampilan/bukti fisik dan kepastian/jaminan. Agar kepuasan pelanggan semakin tinggi terhadap rumah sakit Sarila Husada Sragen pada pasien Rawat Jalan hendaknya direktur rumah sakit meningkatkan tampilan/bukti fisik dengan cara selalu melengkapi sarana dan prasarana rumah sakit. Agar kepuasan pelanggan semakin tinggi terhadap rumah sakit Sarila Husada Sragen pada pasien Rawat Jalan hendaknya Direktur rumah sakit meningkatkan ruang tunggu dan ruang rawat jalan dibuat serapi mungkin terutama supaya pasien merasa nyaman.

6. Penelitian Tulumang, 2015 tentang Tingkat Kepuasan Pasien atas Pelayanan Rawat Jalan di Poli Penyakit Dalam (Interna) di RSU Prof. R. D. Kandou Malalayang. Hasil penelitian menunjukkan ada hubungan antara bukti fisik dengan kepuasan pasien, ada hubungan antara kehandalan dengan kepuasan pasien, ada hubungan antara daya tanggap dengan kepuasan pasien, tidak ada hubungan antara jaminan dengan kepuasan pasien, ada hubungan antara empati dengan kepuasan pasien dan bukti fisik merupakan variabel yang paling dominan terhadap kepuasan pasien di Poli Interna Rumah Sakit Prof. dr. R. D. Kandou Manado.

7. Penelitian Aprila, 2015 tentang pengaruh pelayanan terhadap kepusan pasien rawat jalan di Rumah Sakit Umum Abdul Wahab Syahranie Samarinda. Hasil penelitian menunjukkan Kendalan, daya tanggap, jaminan, perhatian,bukti fisik secara bersamasama berperan dalam meningkatkan kepuasan pasien. Jaminan berperan utama dalam meningkatkan kepuasan pasien rawat jalan RSUD A. Wahab Syahranie Samarinda. Variabel keandalan berpengaruh signifikan terhadap terhadap kepuasan pasien rawat jalan.

\section{Pembahasan}

8. Dari hasil penelitian-penelitian tersebut menunjukkan bahwa semakin baik kualitas pelayanan rumah sakit yang diberikan kepada pasien maka secara signifikan dapat meningkatkan kepuasan pasien rawat jalan di rumah sakit. Kepuasan pasien tergantung pada kualitas pelayanan. Pelayanan adalah semua upaya yang dilakukan karyawan untuk memenuhi keinginan pelanggannya dengan jasa yang akan diberikan. Menurut Zeithaml, Parasuraman dan Berry (dalam Tjiptono, 1997) terdapat lima dimensi pokok yang berkaitan dengan kualitas jasa yang dikenal dengan teori Service Quality yaitu tangibles, reliability, responsiveness, assurance, dan empathy. Menurut Goetsch dan Davis (dalam Zamit, 2005) kualitas merupakan suatu 
kondisi dinamis yang berhubungan dengan produk, jasa, manusia, proses, dan lingkungan yang memenuhi atau melebihi harapan. Menurut Tjiptono (2005), terdapat 5 (lima) sumber kualitas yang dijumpai, yaitu: (1) Program, kebijakan, dan sikap yang melibatkan komitmen dari manajemen puncak; (2) Sistem informasi yang menekankan ketepatan, baik pada waktu maupun detail; (3) Desain produk yang menekankan keandalan dan perjanjian ekstensif produk sebelum dilepas ke pasar; (4) Kebijakan produksi dan tenaga kerja yang menekankan peralatan yang terpelihara dengan baik, pekerja yang terlatih dengan baik, dan penemuan penyimpangan secara cepat; serta (5) Manajemen vendor yang menekankan kualitas sebagai sasaran utama. Menurut Tjiptono (1996), kepuasan atau ketidakpuasan pelanggan adalah respon pelanggan terhadap evaluasi ketidaksesuaian atau dikonfirmasikan yang disesuaikan antara harapan sebelumnya dan kinerja aktual produk yang dirasakan setelah pemakaiannya. Menurut Kotler (1994), kepuasan adalah tingkat perasaan seseorang setelah membandingkan kinerja atau hasil yang dirasakan dibandingkan dengan harapannya. Menurut Engel, et. al (dalam Tjiptono, 1996), kepuasan pelanggan merupakan evaluasi purnabeli dimana alternatif yang dipilih sekurang-kurangnya memberikan hasil (Outcome) sama atau melampaui harapan pelanggan, sedangkan ketidakpuasan timbul apabila hasil yang diperoleh tidak memenuhi harapan pelanggan.

\section{Kesimpulan}

Semakin baik kualitas pelayanan rumah sakit yang diberikan kepada pasien maka secara signifikan dapat meningkatkan kepuasan pasien rawat jalan di rumah sakit. Kepuasan pasien tergantung pada kualitas pelayanan.

\section{Saran}

Pelayanan rumah sakit haruslah semakin ditingkatkan untuk mencapai target terhadap kepuasan pasien, utamanya adalah pasien rawat jalan. Hal ini karena dari hasil studi kepustakaan ini menunjukkan secara signifikan bahwa semakin baik kualitas pelayanan rumah sakit yang diberikan kepada pasien maka dapat meningkatkan kepuasan pasien rawat jalan di rumah sakit.

\section{Ucapan Terima Kasih}

Terima kasih disampaikan kepada:

1. Ketua Stikes Pamenang, Suryono, S.Kep.Ns., MMRS atas motivasi dan kesempatan yang diberikan.

2. Ketua PPPM Stikes Pamenang, Dr. Zauhani KH, SKM., M.Kes. atas dukungan, motivasi dan arahannya.

3. Reviewer Jurnal Ilmiah Pamenang (JIP)

4. Editor Jurnal Ilmiah Pamenang (JIP)

5. Rekan-rekan dosen Stikes Pamenang umumnya dan rekan-rekan dosen prodi S1 Administrasi Kesehatan khususnya.

6. Serta semua pihak yang turut mendukung dalam penyelesaian studi kepustakaan ini.

\section{Daftar Pustaka}

Aprila, Winda, dkk. (2015). Pengaruh Pelayanan Terhadap Kepuasan Pasien Rawat Jalan Di Rumah Sakit Umum Abdul Wahab Syahranie Samarinda. $\quad$ http://ejurnal.untagsmd.ac.id/index.php/EKM/article/view/1546. (diakses dan di unduh pada pkl. 09.30 tgl. 28 April 2020)

Arifah, Umi, dkk. (2013). Pengaruh Kualitas Pelayanan Terhadap Kepuasan Pasien Rawat Jalan di Balai Besar Kesehatan Paru Masyarakat (BBKPM) Surakarta. http://eprints.ums.ac.id/22454/14/10._NASK AH_PUBLIKASI.pdf. (diakses dan di unduh pada pkl. 10.00 tgl. 28 April 2020)

Chairunnisa, dkk. (2015). Gambaran Kepuasan Pasien Rawat Jalan terhadap Pelayanan di Rumah Sakit Islam Jakarta Sukapura (RSIJS).

https://jurnal.umj.ac.id/index.php/JKK/article /download/1567/1366. (diakses dan di unduh pada pkl. 10.00 tgl. 28 April 2020)

J. Tulumang, Stefanus. (2015). Tingkat Kepuasan Pasien atas Pelayanan Rawat Jalan di Poli Penyakit Dalam (Interna) di RSU Prof. R. D. Kandou Malalayang - Manado. https://ejournal.unsrat.ac.id/index.php/jikmu/ article/download/7861/7946. (diakses dan di unduh pada pkl. 10.15 tgl. 28 April 2020)

Mirzaqon. T, A dan Budi Purwoko. (2017). Studi Kepustakaan Mengenai Landasan Teori dan Praktik Konseling Expressive Writing. Jurnal BK Unesa, 8 (1).

Rensiner, dkk. (2018). Analisis faktor kualitas pelayanan terhadap kepuasan pasien rawat jalan RSUD dr. Achmad Darwis. http://jurnal.fk.unand.ac.id/index.php/jka/arti cle/download/817/673. (diakses dan di unduh pada pkl. 09.30 tgl. 28 April 2020)

Sellang, Kamaruddin. Dkk. (2019). Strategi Dalam Peningkatan Kualitas Pelayanan Publik: Dimensi, Konsep, Indikator dan Implementasinya. 
https://books.google.co.id/books?id=U06rDw AAQBAJ\&printsec $=$ frontcover\&dq $=$ Kualitas + Pelayanan\&hl=id\&sa=X\&ved=0ahUKEwi UvbLc7ajpAhWRUn0KHRXKD8oQ6AEILz $\mathrm{AB} \# \mathrm{v}=$ onepage \&q$=$ Kualitas\%20Pelayanan\& $\mathrm{f}=$ false. Penerbit Qiara Media

Supartiningsih, Solichah. (2017). Kualitas Pelayanan Kepuasan Pasien Rumah Sakit: Kasus Pada Pasien Rawat Jalan. https://journal.umy.ac.id/index.php/mrs/articl e/download/2342/pdf_3. (diakses dan di unduh pada pkl. 10.10 tgl. 28 April 2020)

Tjiptono, Fandy. (1996). Manajemen Jasa. Yogyakarta: Andi Offset.____ (1997). Prinsip-prinsip Total Quality Service (TQS). Yogyakarta: Andi Offset.___ (2005). Service, Quality, and Satisfaction. Yogyakarta: Andi Offset.

Utami, Amelia Tri, dkk. (2013). Pengaruh Kualitas Pelayanan Terhadap Kepuasan Pasien. JKMP (ISSN. 2338-445X), Vol. 1, No. 1, Maret 2013, 1-110. http://ojs.umsida.ac.id/index.php/jkmp/article /download/429/364. (diakses dan di unduh pada pkl. 10.10 tgl. 28 April 2020)

Zamit, Yulian. (2005). Manajemen Kuantitatif. Yogyakarta: BPFE 